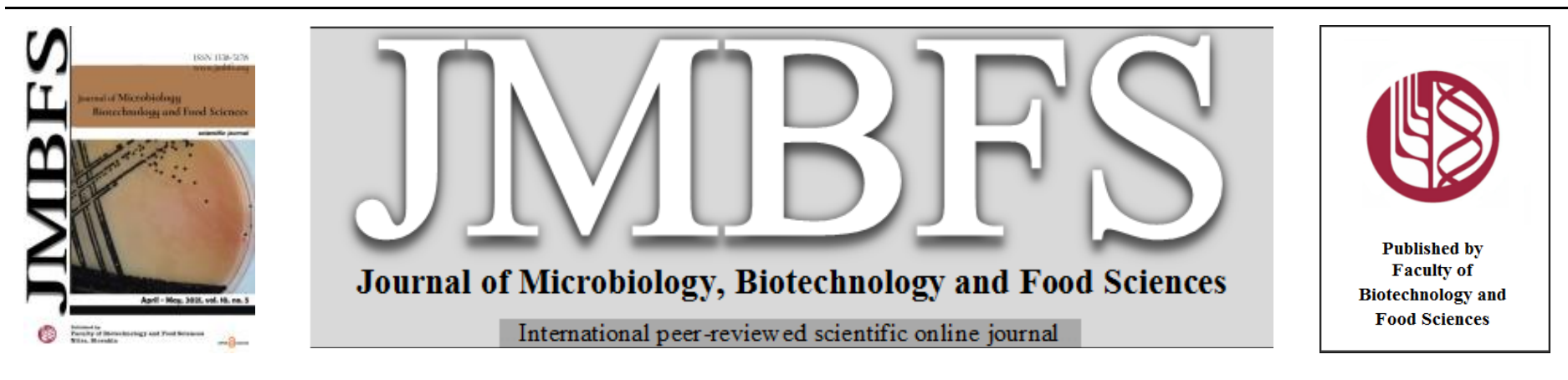

\title{
PHYSICOCHEMICAL PROPERTIES OF CHEMICALLY INTERESTERIFIED VEGETABLE OILS
}

\author{
Farhan Aslam ${ }^{1}$, Sanaullah Iqbal ${ }^{1}$, Hafiza Bushra Tariq ${ }^{2}$, Muhammad Imran $^{3, *}$, Maksim Rebezov $^{4,5}$, Vladimir Chumakov ${ }^{6}$, Nadezhda $^{2}$ \\ Kenijz $^{7}$, Mohammad Ali Shariati ${ }^{4,5,8, *}$
}

\author{
$\operatorname{Address(es):~}$ \\ ${ }^{1}$ Department Of Food Science and Human Nutrition, University of Veterinary and Animal Sciences Lahore. \\ ${ }^{2}$ Institute of Agricultural Sciences, University of the Punjab Lahore. \\ ${ }^{3}$ University Institute of Diet and Nutritional Sciences, Faculty of Allied Health Sciences, The University of Lahore-Lahore, Pakistan. \\ ${ }^{4}$ V M Gorbatov Federal Research Center for Food Systems of Russian Academy of Sciences, 26 Talalikhina St., Moscow, 109316, Russian Federation. \\ ${ }^{5}$ Prokhorov General Physics Institute of the Russian Academy of Science, 38, Vavilova str., Moscow, 119991, Russian Federation. \\ ${ }^{6}$ Kurgan State Agricultural Academy by T.S. Maltsev, Lesnikovo village, Ketovsky district, Kurgan region, 641300, Russian Federation. \\ ${ }^{7}$ Kuban State Agrarian University named after I.T. Trubilin, 13 Kalinina St., Krasnodar, 350044, Russian Federation. \\ ${ }^{8}$ K.G. Razumovsky Moscow State University of technologies and management (the First Cossack University), Moscow, Russian Federation.
}

*Corresponding author: mic_1661@yahoo.com ; shariatymohammadali@gmail.com

https://doi.org/10.15414/jmbfs.4291

\section{ARTICLE INFO}

Received 4. 6. 2020

Revised 30. 12. 2020

Accepted 5. 1.2021

Published 1. 4. 2021

Regular article open ${ }_{\text {ACCESS }}$

\begin{abstract}
Interesterification is an alternative to partial hydrogenation that helps to manufacture products of a variety of melting properties. When the process is applied to different blends of vegetable oils, redistribution of fatty acids between and within triacyglycerol occurs that changes the physical properties especially the melting characteristics of the vegetable oil blends. For chemical interesterification process, unrefined vegetable oils (soybean oil and cottonseed oils) were obtained from the local industry (United Industries Faisalabad, Pakistan). Different blends of soybean and cottonseed oils were prepared ranging from 100\% soybean oil to $100 \%$ cottonseed oil in 25\% increments (w/w) with different ratios of $(100 \%: 0 \%, 75 \%: 25 \%, 50 \%: 50 \%, 25 \%: 75 \%, 0 \%: 100 \%)$ respectively. The blended oil portions $(500 \mathrm{~mL})$ were neutralized and dried. For chemical interesterification sodium methoxide was used as catalyst. At the end of reaction, the catalyst was inactivated and reaction was stopped by the addition of citric acid solution and at the end by the addition of warm water $\left(70-80^{\circ} \mathrm{C}\right)$. Interesterified oils were bleached by heating them to $110^{\circ} \mathrm{C}$ and mixing with bleaching earth and then the hot interesterified oils were filtered and cooled. Physico-chemical properties (refractive index, specific gravity, colour, melting point, free fatty acids, iodine value, peroxide value, saponification value and rancidity) and sensory evaluation (appearance, odor and overall acceptability) of the final product was conducted at 0,15 and 30 days of interval. The results revealed that refractive index, specific gravity, color, melting point, free fatty acids value, peroxide value and saponification value increased while iodine value decreased with the passage of time. Further studies showed that storage had a highly significant effect on color, melting point, free fatty acids value, iodine value, peroxide value and saponification value. The effect of storage was non-significant for parameters like specific gravity and refractive index.
\end{abstract}

Keywords: Vegetable oils, Chemical interesterification, Physico-chemical properties

\section{INTRODUCTION}

Fats and oils are constructed of building blocks called "triglycerides" resulting from the combination of one unit of glycerol and three units of fatty acids. They are insoluble in water but soluble in most organic solvents (Hui, 1996). They have lower densities than water, and may have consistencies at ambient temperature of solid, semisolid, or clear liquid. When they are solid-appearing at a normal room temperature, they are referred to as "fats" and when they are liquid at that temperature, they are called "oils." For simplification purposes, the terms "fat" and "oils" are used interchangeably (O'Brien, 2004).

Vegetable fats and oils are substances derived from plants that are composed of triglycerides. Nominally, oils are liquid at room temperature, and fats are solid; a dense brittle fat is called a wax. Although many different parts of plants may yield oil, in actual commercial practice oil is extracted primarily from the seeds of oilseed plants. The physical characteristics of a fat or oil are dependent upon the degree of unsaturation, the length of the carbon chains, the isomeric forms of the fatty acids, molecular configuration, and processing variables (Nawar, 1996; Hosseinian et al., 2004). Examples of edible animal fats are lard, fish oil, and butter or ghee. They are obtained from fats in the milk, meat and under the skin of the animal. Examples of edible plant fats are peanut, soybean, sunflower, sesame, coconut, olive and vegetable oils. Margarine and vegetable shortening, which can be derived from the above oils, are used mainly for baking (Smith and Minor, 1974)
Interesterification is one of the four modification processes to alter the physicochemical characteristics of oils and fats, the others being blending, fractionation and hydrogenation (Dimick, 1991). Interesterification is an acyl-arrangement reaction. Interesterification involves redistribution of the fatty acids between and within triacylglycerols. The resulting product presents the same total fatty acid composition of the original fat, but the triacylglycerol (TAG) positional distribution and physical properties are altered after the process (Konishi $\boldsymbol{e}$ al., 1993). This rearrangement process does not change the composition of the fatty acids from the starting materials. With the rising concerns over the nutritional impact of trans fatty acids on health, interesterification has become more popular for the preparation of low or zero trans functional plastic fats. The production of edible fats requires fat blends that are able to impart plasticity to products such as margarine and shortening (Rousseau et al., 1996). To achieve these properties, fat blends may be chemically modified.

Chemical interesterification is carried out by blending the desired oils, drying them, and adding a catalyst such as sodium methoxide. When the reaction is completed, the catalyst is neutralized and the rearranged product is washed, bleached, and deodorized to give a final oil product with different characteristics than the original oil blends (Norizzah et al., 2004). Sodium methoxide is used as a catalyst in chemical interesterification which produces complete positional randomization of the acyl groups in the triacylglycerols (Petrauskaite $\boldsymbol{e t}$ al., 1998). Oil exists in two forms, cis and trans form. The cis configuration is a bent molecule, whereas the trans configuration is a straight chain. In the cis configuration, the two carbon moieties are on the same side of the double bond 
and on opposite sides in the trans configuration (Idris and Dian, 2005). High consumption of dietary fat is associated with both increased body fat and obesity. As they are saturated, tend to raise the level of blood cholesterol rather than lower it, increasing risk of cardiovascular disease. Therefore, diet and health concerns in recent years have resulted in consumers having an increased interest in reduced and low-calorie foods (Rodrigues and Gioielli, 2003).

Interesterification raises the melting range of these oils by introducing saturated fatty acids to the $s n-2$ position of glycerol and, thus, increasing the disaturated and trisaturated triacylglycerol (TAG) species (Pfeuffer $\boldsymbol{e t}$ al., 1995). The fatty acid profile of the oil is not changed. Undirected interesterification is performed at temperatures higher than the melting points of possible triacylglycerol, and the fatty acids are randomly reassigned to the glycerol positions. In directed interesterification, which is performed at lower temperatures, high-melting triacylglycerols are selectively formed by crystallization and removed from the equilibrium (Rodriguez et al., 2001). Interesterification can be viewed as a more "natural" process than hydrogenation because it does not change the acyl groups in the triacylglycerol. Sodium methoxide is the most commonly used catalyst and it can be easily washed out of the fat with water (Sreenivasan, 1978; Mascioli $\boldsymbol{e}$ al., 1999)

Margarine or other plastic fats are normally produced by hydrogenation, fractionation, chemical transesterification or a combination of these methods which offer the possibility of changing the physical and chemical characteristics of lipids (Zhang et al., 2000). In the production of plastic fats, hydrogenation hardens oils while interesterification (IE) blends soft oils with hard fats to a desired functionality and consistency. Palm oil and its hard fraction, stearin, are excellent hard stocks for interesterification (IE). By combining IE and other modification processes, many products such as shortenings, margarines and vegetable ghee with low trans or no trans at all can be formulated. Chemical transesterification is a method used to achieve a complete positional randomization of acyl groups in triacylglycerols chain (Hurtova et al., 1996) Rearrangement of fatty acids on their glycerol backbone (transesterification) offers the possibility of changing the physical characteristics, especially the crystallization properties of fats and oils. Recently, chemical transesterification is increasing in the industrial margarine production for the benefit of avoiding trans fatty acid formation and providing zero trans margarine in which fully hydrogenated fats are blended with liquid oils as the feedstocks of transesterification (Schmidt et al., 1996).

Interesterification is an alternative process for hydrogenation in the production of plastic fats such as margarine, shortening and even vanaspati (Zeitoun $\boldsymbol{e t}$ al. 1993). The production of edible fats requires fat blends that are able to impart plasticity to products such as margarine and shortening. To achieve these properties, fat blends may be chemically interesterified. Chemica interesterification also requires low initial investment and operation cost (Liu, 2004; Idris and Dian, 2005). It also helps to control the coronary heart disease, diabetes, high blood pressure, stroke and certain cancers. Chemica interesterification helps to control obesity because it helps to control the cholesterol level in the body (Dogan $\boldsymbol{e t}$ al., 2007). The random or chemical IE is the most applied IE modification process of oils and fats as it is simpler, cheaper and easier to carry out compared to directed or enzymatic IE.

\section{MATERIAL AND METHODS}

For this research work that comprises the physico-chmical properties of chemically interesterified vegetable oils, we followed the following procedure.

\section{Procurement of raw materials}

Unrefined vegetable oils (soybean oil and cottonseed oil) were obtained from local oil industry (United Industries Limited, Faisalabad). Detail of the method by which, we did the chemical interesterification of edible vegetable oils is as follows.

\section{Blend preparation}

Liquefied soybean oil and cottonseed oil were mixed in proportions ranging from $100 \%$ soybean oil to $100 \%$ cottonseed oil in $25 \%$ increments (w/w) as mentioned in table 1 .

Table 1 mix rate of soybean oil and cotton seed oil

\begin{tabular}{cc}
\hline Soybean oil\% & Cottonseed oil\% \\
\hline 100 & 0 \\
75 & 25 \\
50 & 50 \\
25 & 75 \\
0 & 100 \\
\hline
\end{tabular}

\section{Oil refining}

Each of the prepared blends was placed into a round bottom flask (1000 mL). For an optimum interesterification reaction, the blended oil portions $(500 \mathrm{~mL})$ was neutralized and dried to ensure the good results and to optimize the catalys activity. Portions $(500 \mathrm{~mL})$ of the blends were heated to about $110^{\circ} \mathrm{C}$ to remove moisture and air bleaching was also done by using the 5\% bleaching earth (bentonite clay).

\section{Addition of catalyst}

For chemical interesterification, sodium methoxide was used as catalyst $(0.2 \%)$ When the blend had reached the temperature of $110-120^{\circ} \mathrm{C}$, it was kept at that temperature for some period of time for the appropriate removal of moisture. Now the temperature was lowered down to reaction temperature of $80^{\circ} \mathrm{C}$, sodium methoxide, $0.2 \%$ (w/w), was added while the blend was vigorously stirred. The interesterification reactions were performed under constant agitation for 60 minutes. The temperature was then decreased $\left(60^{\circ} \mathrm{C}\right)$

\section{Reaction stop}

To stop the reaction, an excess of citric acid (4\%) were added to neutralize the catalyst. The excess of citric acid and sodium methoxide was removed with warm water washes $\left(70-80^{\circ} \mathrm{C}\right)$ and the interesterified blends were vacuum-dried Residual water was removed with an excess of anhydrous sodium sulfate (15\%), followed by filtration through Whatman \#2 filter paper. The washing process was repeated several times to ensure that the sample was completely clean of citric acid, residual catalyst, and the resulting soaps formed by the reaction between sodium ion and any free fatty acids present or produced during the process.

\section{Post bleaching}

Oil was bleached by heating it to $110^{\circ} \mathrm{C}$ and mixing with clay (bentonite). The mixture was held for several minutes and then the hot oil was filtered from the clay and was cooled and stored. After this the following physico-chemical analysis was done.

\section{Physico-chemical properties}

The following physico-chemical properties were evaluated for each blend. Among the physical properties following aspects were analyzed. Specific gravity by (AOAC, 1990), Color by (AOCS, 1989), Melting point by (AOCS, 1989).

Among the chemical properties following aspects were analyzed.

Free fatty acid value by (AOCS, 1989), Iodine value by (Wij's method), Saponification value by (AOAC, 1990).

\section{Rancidity test}

\section{Physical properties}

\section{Refractive index}

Refractive index (RI) of interesterified oils was determined by AOCS (1989) method by means of Abbe's refractometer at room temperature. It is principally designed for quick determination of the refractive index of small quantities of liquids. First sample was melted and filtered through the filter paper to remove any impurities. The prisms of refractometer were cleaned with acetone and dried. The instrument was calibrated with distilled water. It was again cleaned with acetone and dried. After this a drop of oil of each sample was placed between the prisms one by one. The telescope was rotated; the field of view was divided into bright and dark portions. When end of bright portion was coinciding with the wire of the telescope, the refractive index on the scale at room temperature was noted.

\section{Specific gravity}

Specific gravity of final product was determined by AOAC (1990) method by means of Pycnometer at $25^{\circ} \mathrm{C}$. Specific gravity bottle (Pycnometer) was used to determine the specific gravity of oils. First sample was melted and filtered through the filter paper to remove any impurities. Weight of empty bottle was determined, then the bottle was filled with water and its weight with water was determined. Empty weight bottle was filled oil to overflowing, in such a manner to avoid the entrapment of air bubbles. Then the weight of bottle along with contents was done, and the specific gravity was calculated with the following formula.

$$
\text { Specific gravity at } 25^{\circ} \mathrm{C} / 25^{\circ} \mathrm{C}=\frac{A-B}{C-B}
$$


Where, $\mathrm{A}=$ weight in gm of specific gravity bottle with oil at $25^{\circ} \mathrm{C}$

$\mathrm{B}=$ weight in gm of specific gravity bottle at $25^{\circ} \mathrm{C}$

$\mathrm{C}=$ weight in gm off specific gravity bottle with water at $25^{\circ} \mathrm{C}$

\section{Color}

Color of interesterified final product was determined by AOCS (1989) method by means of Lovibond Tintometer. First sample was melted and filtered through the filter paper to remove any impurities and foreign matters. The color of the oils was measured by comparison with standard colored glasses (red and yellow) in a Lovibond Tintometer using 5.25" cell. The cell of the lovibond tintometer was rinsed with the oil of which color was to be measured and then the sample was taken in it and the reading was taken. The results were expressed as the number of glass standards (red and yellow).

\section{Melting Point}

Melting point of different blended interesterified oils was determined by AOCS (1989) capillary tube method. Sample was melted and filtered through the filte paper to remove any impurities. Thoroughly mixed the sample for which the melting point test carried out. The sample was heated up on oven until it converted from semi-solid to liquid state. Thermometer $0^{\circ} \mathrm{C}-100^{\circ} \mathrm{C}$ immersed in water previously cooled to $4^{\circ} \mathrm{C}-5^{\circ} \mathrm{C}$, contained in $250 \mathrm{ml}$ beaker having a stirrer. Filled 2-3 capillary tubes from the sample solidify with ice and attached with mercury bulb of the thermometer. Filled portion of the capillary tube was below the water level of the beaker. Water was heated up gently with spirit lamp followed by gently stirring. Noted the temperature at which the sample was completely melted. It was the melting point of sample oil.

\section{Chemical properties}

\section{Free fatty acids value}

Free fatty acids value of interesterified products was determined by AOCS (1989) method. Sample was melted and filtered through the filter paper to remove any impurities. Take $10 \mathrm{gms}$ of well mixed and entirely liquid oil in a $250 \mathrm{ml}$ conical flask. Added specified quantity of hot neutralized alcohol $(50 \mathrm{ml})$ in it. Added 2-3 drops of phenolphthalein (1\%) indicator. Titrate it against $0.1 \mathrm{~N}$ $\mathrm{NaOH}$ solution shaking vigorously to the appearance of first permanent pink color end point. Free fatty acid value was calculated as below:

$$
\text { Free Fatty Acid Value }=\frac{M L \text { of } \mathrm{NaOH} \text { used } \times N \times 28.2}{\text { Weigh of Samples }}
$$

Where ML is Milliliters of $\mathrm{NaOH}, \mathrm{N}$ is Normality of $\mathrm{NaOH}$.

\section{Iodine value}

Iodine value (IV) of interesterified products was determined by wij's method. Sample was melted and filtered through the filter paper to remove any impurities. $0.2 \mathrm{gm}$ of the oil sample was taken into $500 \mathrm{ml}$ iodine flask and dissolved in 25 $\mathrm{ml} \mathrm{CHCL}_{3} .25 \mathrm{ml}$ of wij's solution was added in it and let it stand for 50 minutes in a dark with shaking occasionally. $20 \mathrm{ml}$ of $10 \% \mathrm{KI}$ solution was added. Shaked thoroughly and $10 \mathrm{ml}$ distilled water was added. Wash down any free iodine on the stopper. Titrated iodine with standard $0.1 \mathrm{~N}$ sodium thiosulphate solution until yellow solution turned almost colorless. Few drops of starch solution were added as indicator and continued titration until blue coloration disappeared. At the end of titration, bottle was stoppered and shaked violently so that any iodine remaining in solution in $\mathrm{CHCL}_{3}$ was taken up by $\mathrm{KI}$ solution. Also conducted a blank determination without the sample. Number of $\mathrm{ml}$ of $0.1 \mathrm{~N} \mathrm{Na}{ }_{2} \mathrm{~S}_{2} \mathrm{O}_{3}$ required by blank (b) minus number of ml used by sample gave $\mathrm{Na}_{2} \mathrm{~S}_{2} \mathrm{O}_{3}$ equivalent of iodine absorbed by oil. Iodine value was calculated as below:

$$
\text { Iodine value }=\frac{(B-S) \times N \times 12.69}{W}
$$

Where B is Vol. of $0.1 \mathrm{~N} \mathrm{Na}_{2} \mathrm{~S}_{2} \mathrm{O}_{3}$ used for blank, $\mathrm{S}$ is Vol. of $0.1 \mathrm{~N} \mathrm{Na}{ }_{2} \mathrm{~S}_{2} \mathrm{O}$ used for sample and $\mathrm{N}$ is Normality of $\mathrm{Na}_{2} \mathrm{~S}_{2} \mathrm{O}_{3}$ and $\mathrm{W}$ is Weight of oil taken.

\section{Peroxide value}

Peroxide value of interesterified products was determined by AOAC (1990) method. Sample was melted and filtered through the filter paper to remove any impurities. $5.0 \mathrm{gm}$ of oil sample was taken in a $250 \mathrm{ml}$ iodine flask provided with well fitted glass stopper, added in it $30 \mathrm{ml}$ of solution mixture (acetic acid and chloroform $3: 2$ ), swirled the flask until the oil dissolved completely. Add 0.5 $\mathrm{ml}$ of saturated and freshly prepared KI solution. Allowed it to stand for about two minutes with occasional shaking and added $30 \mathrm{ml}$ of distilled water. Titrated the liberated iodine against $0.1 \mathrm{~N}$ sodium thiosulphate solution adding it gradually. Unless the yellow color almost disappears. Add $0.5 \mathrm{ml}$ of starch solution as indicator and continued the titration with vigorous shaking, until the blue color disappeared. A blank reading was taken under the similar conditions at the same time. The peroxide value was calculated by using following equation:

$$
\text { Peroxide Value }=\frac{(B-A) \times N \times 1000}{W}
$$

Where B is Vol. of $\mathrm{Na}_{2} \mathrm{~S}_{2} \mathrm{O}_{3}$ used for blank, A is Vol. of $\mathrm{Na}_{2} \mathrm{~S}_{2} \mathrm{O}_{3}$ used for sample, $\mathrm{N}$ is Normality of $\mathrm{Na}_{2} \mathrm{~S}_{2} \mathrm{O}_{3}$, and $\mathrm{W}$ is Weight of the oil taken.

\section{Saponification value}

Saponification value of interesterified product was determined by AOAC (1990) method. First sample was melted and filtered through the filter paper to remove any impurities. Accurately weighed $2.0 \mathrm{gm}$ of the oil in a flask and refluxed it with $25 \mathrm{ml}$ of $0.5 \mathrm{~N}$ alcoholic potassium hydroxide on a water bath for 50 minutes cooled to room temperature and titrated against $0.5 \mathrm{~N} \mathrm{Hcl}$ solution using phenolphthalein as indicator. Carried out a blank determination simultaneously without adding the oil. The saponification value (S.V) was calculated as below:

$$
\text { Chronic Renal Failure }=\frac{(X-Y) \times N \times 56.01}{W}
$$

$\mathrm{X}=$ Blank reading, $\mathrm{Y}=$ Actual reading, $\mathrm{W}=\mathrm{Weight}$ of oil

\section{Rancidity}

Rancidity of product was analyzed by AOAC (1990) method by Kries method First sample was melted and filtered through the filter paper to remove any impurities. Take rancidity cylinder of $50 \mathrm{ml}$ with stopper. The cylinder was dry and clean. Added $10 \mathrm{ml}$ well melted and entirely liquid sample and $10 \mathrm{ml}$ of phloroglucinol solution $0.1 \%$ and shaked well. Added $10 \mathrm{ml}$ of concentrated $\mathrm{Hcl}$ solution and again shaked well. Some samples showed pink color which showed that rancidity occurred during storage.

\section{Sensory evaluation}

All the interesterified blended oils were rated for appearance, odor, and overall acceptability. A panel of five judges from the National Institute of Food Science and Technology evaluated the samples for the appearance, odor and overall acceptability as described by Larmond (1987).

\section{Statistical analysis}

The data for each parameter were subjected to statistical analysis to determine the level of significance by using Duncan multiple range (DMR) test (Steel $\boldsymbol{e t}$ al. 1997).

\section{RESULTS AND DISCUSSION}

Research work was conducted to evaluate the physico-chemical properties of chemically interesterified vegetable oils. Different blends of soybean and cottonseed oils B1(100\%: 0\%), B2 (75\%: 25\%), B3 (50\% 50\%), B4 (25\%: $75 \%)$ and B5 (0\%: $100 \%)$ were prepare and then chemical interesterification was done by using sodium methoxide as catalyst. After chemical interestification, physicochemical analysis was done whose results are described below.

\section{Refractive index}

The results revealed to the refractive index of different chemically interesterified vegetable oil blends B1, B2, B3, B4, and B5 were found and is presented in (figure 1 and 2). It is evident from the data presented in figures that there is an increase in the refractive index with increasing time interval under ambient storage conditions which is in correlation with the results as observed by (AlZamily and Al-Hakim 1987; Tyagi and Vasishtha 1996). The statistical analysis shows the changes between the refractive index values have no significant effect during storage. The general trend is a sort of increase with the increase in storage time. 


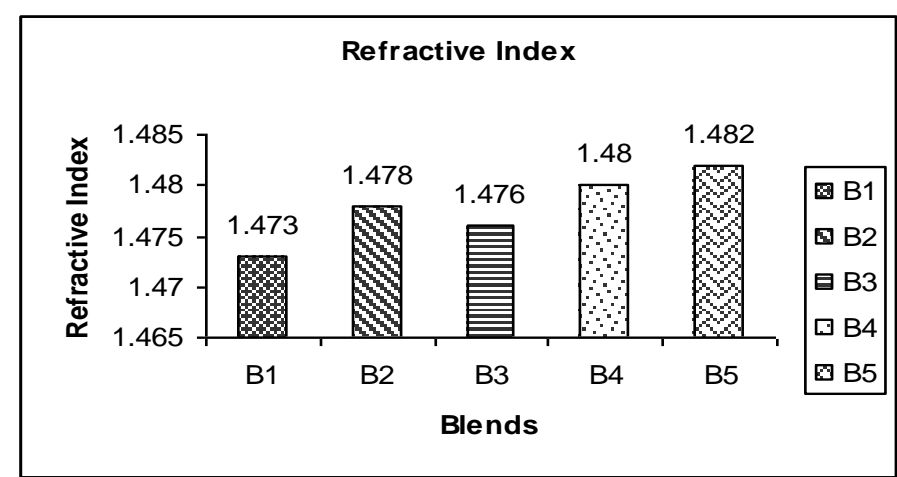

Figure 1 Refractive index of different blends

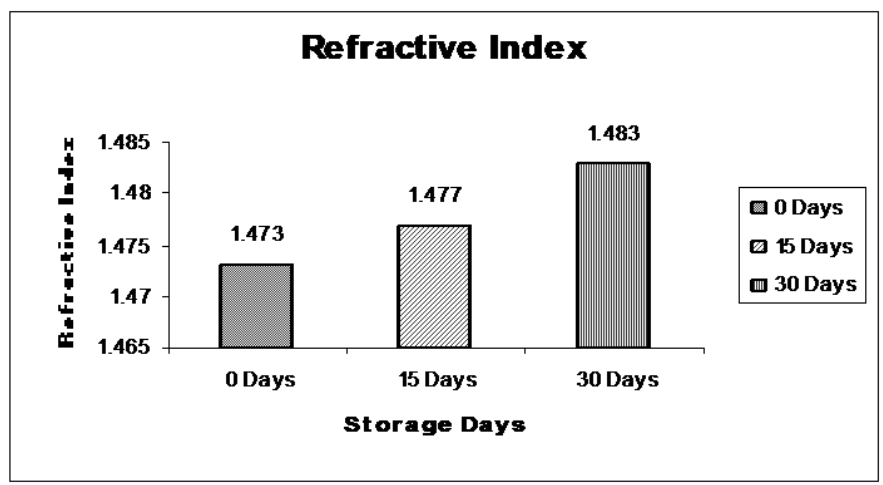

Figure 2 Effect of storage on refractive index

\section{Specific gravity}

The results revealed to the specific gravity of different chemically interesterified vegetable oil blends B1, B2, B3, B4, and B5 were found and is presented in (figure 3 and 4). The statistical analysis shows that there is an increase in the specific gravity with increasing time interval under ambient storage conditions which is in correlation with the results as observed by (Timms 1985; Tyagi and Vasishtha 1996; Hosseinian et al. 2004). Increase in the specific gravity under ambient storage conditions may be due to the polymerization that makes it denser and as a result causes an increase in specific gravity. The results also revealed that the changes between the values of specific gravity of each type of blend are non-significant.

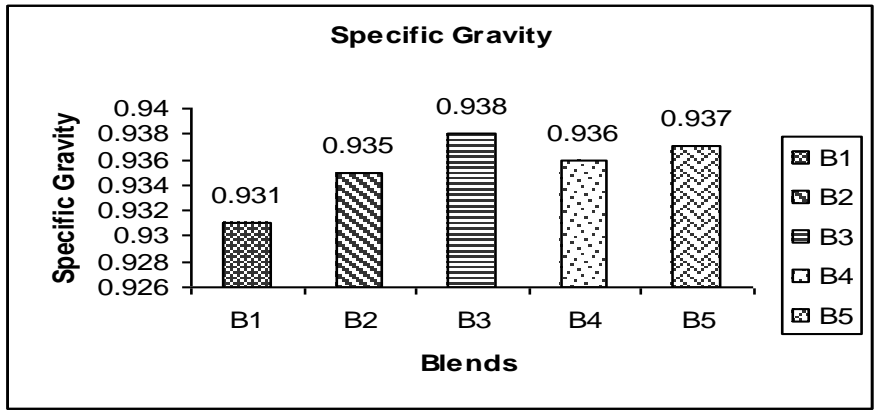

Figure 3 Specific gravity of different blends

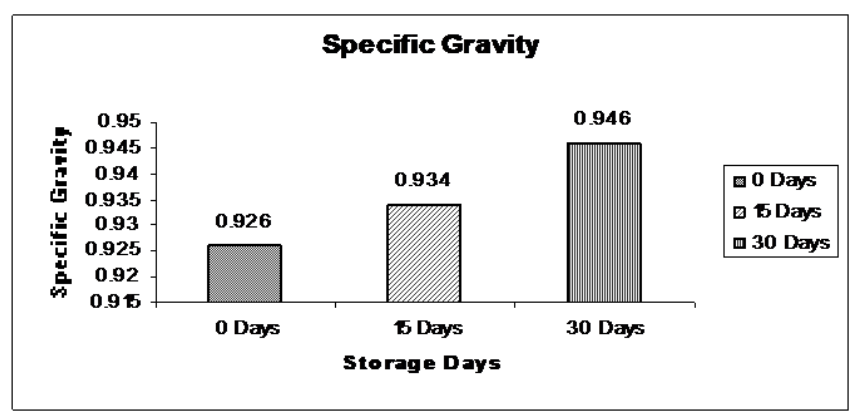

Figure 4 Effect of storage on specific gravity
Color

The results revealed to the color (Red and Yellow) of different chemically interesterified vegetable oil blends B1, B2, B3, B4, and B5 were found and is presented in (figure 5, 6, 7 and 8). The results show that the color difference between different blends of chemically interesterified oils is less significant as compared to color values during storage which is in correlation with the results as observed by (Yoon et al., 1987; Smith and Minor 1974). Maximum color value was found after 30 days storage period interval. The statistical analysis shows that the color of chemically interesterified vegetable oils becomes darker with the increase in storage period. This change in color is due to presence of phenolic compounds. Similar types of results were observed by (Shiela et al., 2004). Proper bleaching and cleaning should be done to avoid the change in color and the phenolic compounds should be reduced to minimum level during processing conditions. Study of the color change alone is not considered a good test for assessing the quality of different vegetable oils, though it is useful to check the other properties of oil.

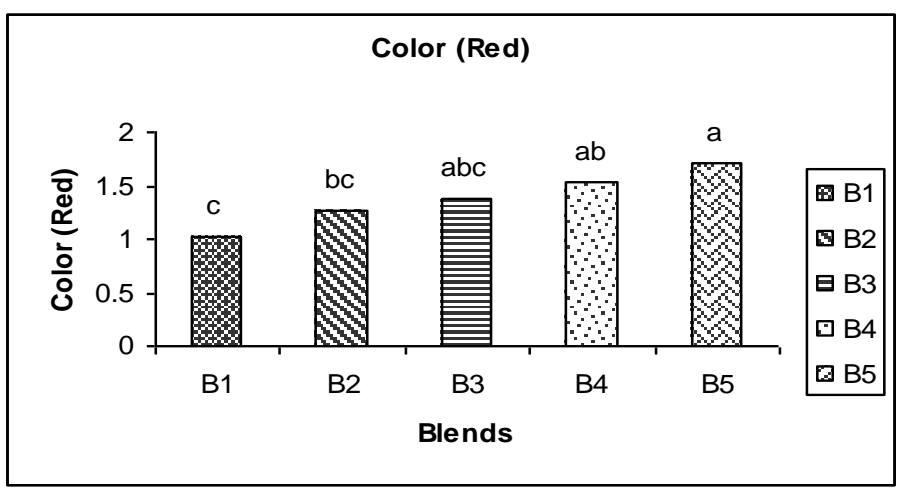

Figure 5 Red color of different blends

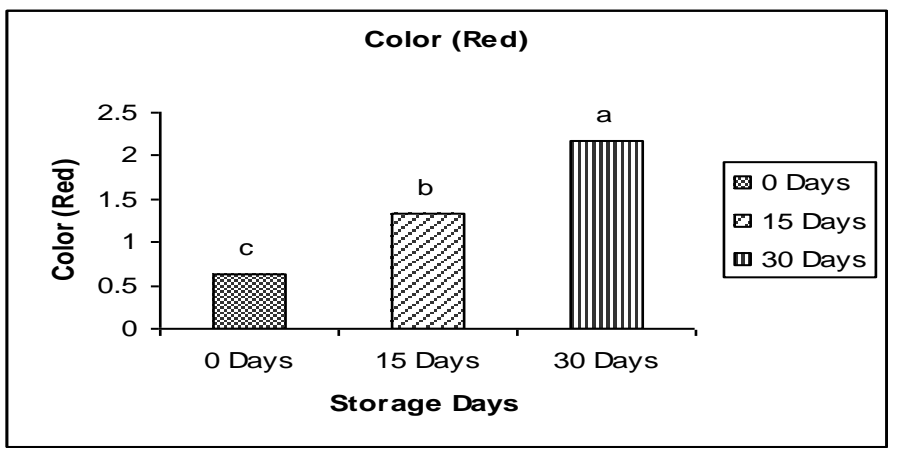

Figure 6 Effect of storage on red color

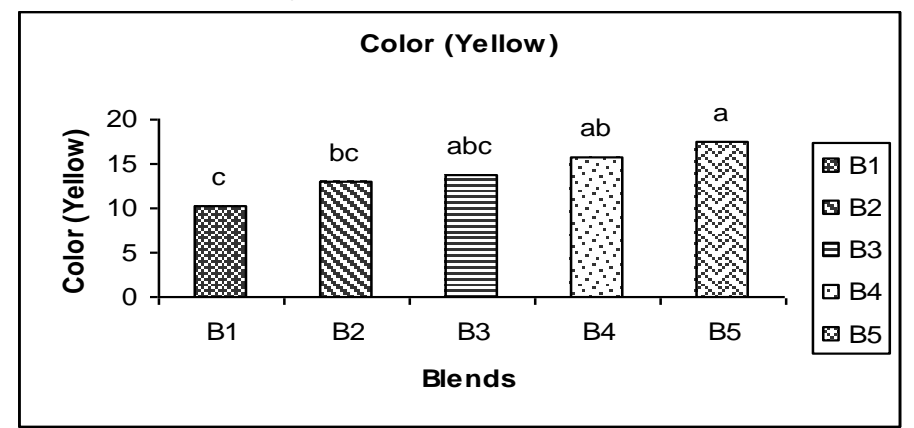

Figure 7 Yellow color of different blends

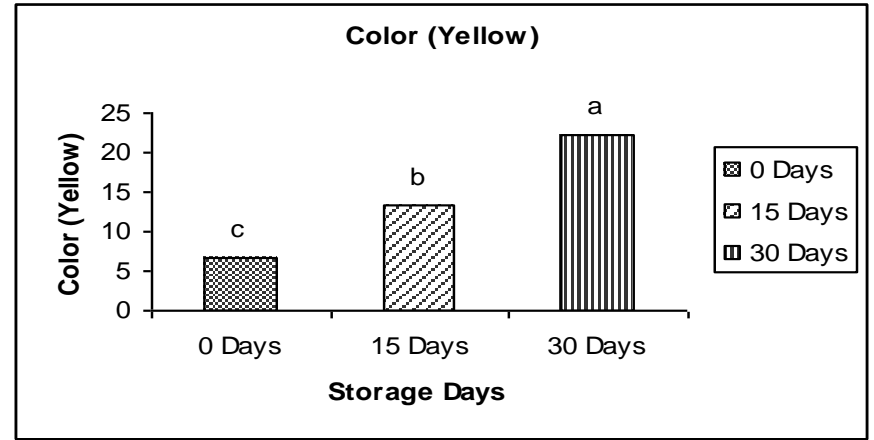

Figure 8 Effect of storage on yellow color 


\section{Melting point $\left({ }^{\circ} \mathrm{C}\right)$}

The results revealed to the specific gravity of different chemically interesterified vegetable oil blends B1, B2, B3, B4, and B5 were found and is presented in (figure 9 and 10). The statistical analysis shows that, the melting point difference between different blends of chemically interesterified vegetable oil blends is more significant as compared to melting point values during storage period. Similar types of results were observed by (Zeitoun et al., 1993; Boyaci et al. 2003). The maximum melting point value was found after 30 days storage period interval. The results show that melting point value was increased during storage which is in correlation with the results as observed by (Norizzah et al., 2004; Fattahi-far et al., 2006). Interesterification may increase or decrease the melting point of an oil/fat. Randomization of liquid vegetable oils may cause an increase in melting point.

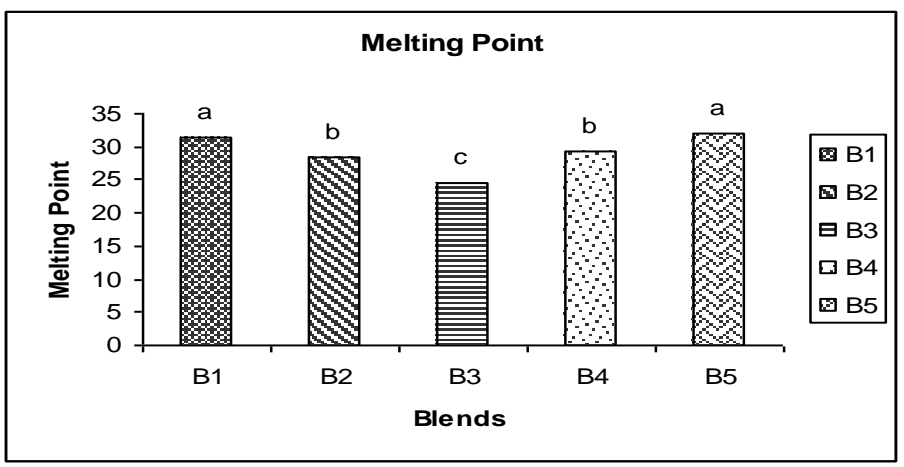

Figure 9 Melting point of different blends

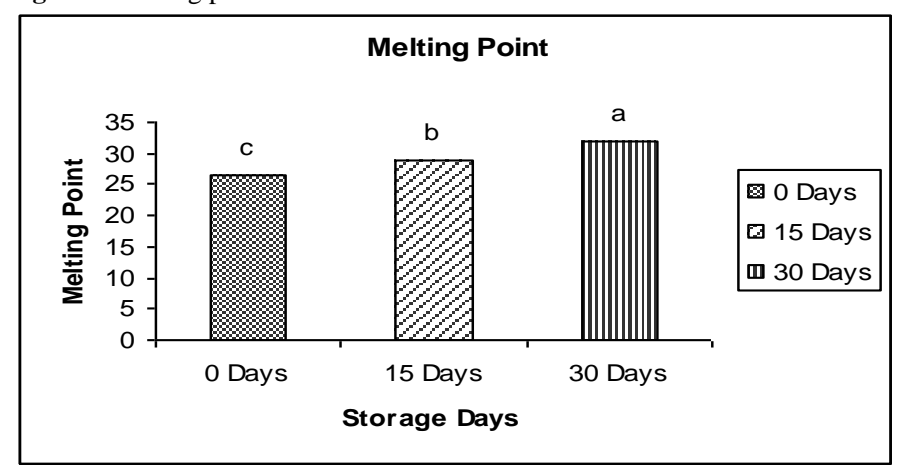

Figure 10 Effect of storage on melting point

\section{Free fatty acids value}

The results revealed to the free fatty acids value of different chemically interesterified vegetable oil blends B1, B2, B3, B4, and B5 were found and is presented in (figure 11 and 12). The results revealed that as the storage period increases, the free fatty acids value was also increased which is in correlation with the results as observed by (Petrauskaite et al., 1998; Kowalski et al., 2004). The free fatty acid value difference between different blends of interesterified oils is less significant as compared to free fatty acid value during storage. Similar types of results were observed by (Ramli et al., 2005). For each oil blend, maximum free fatty acid value was observed after storage period of 30 days interval.

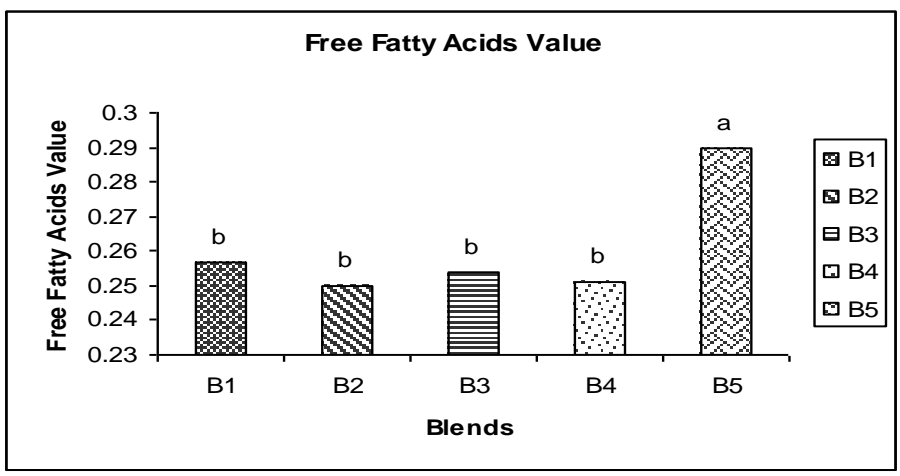

Figure 11 Free fatty acids value of different blends

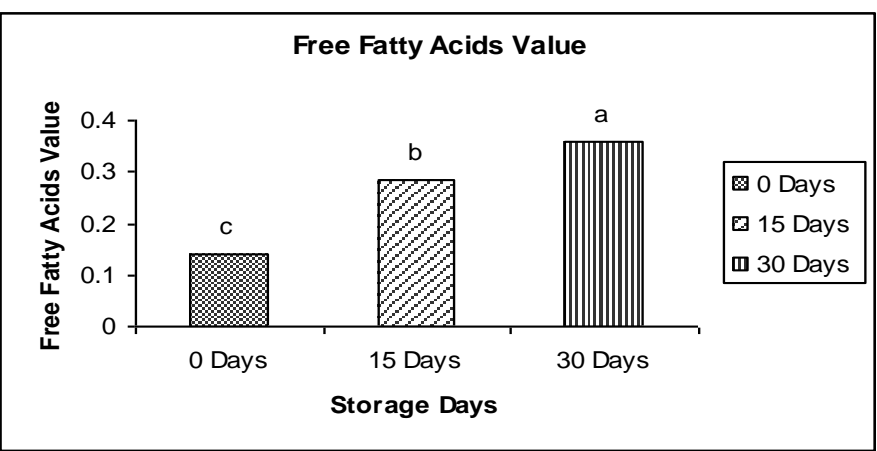

Figure 12 Effect of storage on free fatty acids value

\section{Iodine value}

The results revealed to the iodine value of different chemically interesterified vegetable oil blends B1, B2, B3, B4, and B5 were found and is presented in (figure 13 and 14). The statistical analysis shows a considerable decrease in iodine value as the storage period increased, iodine value decreased during storage which is in correlation with the results as observed by (Karabulut $\boldsymbol{e t}$ al., 2004; Ramli et al., 2005). Maximum decrease was observed after 30 days of time interval. The result shows that iodine value difference between different blends of chemically interesterified oils is less significant as compared to iodine value during storage. Similar types of results were observed by (Cho and Deman 1993; Daniels et al., 2006). As the storage increased the iodine value of different chemically interesterified blended vegetable oils (soybean and cottonseed oils) was decreased.

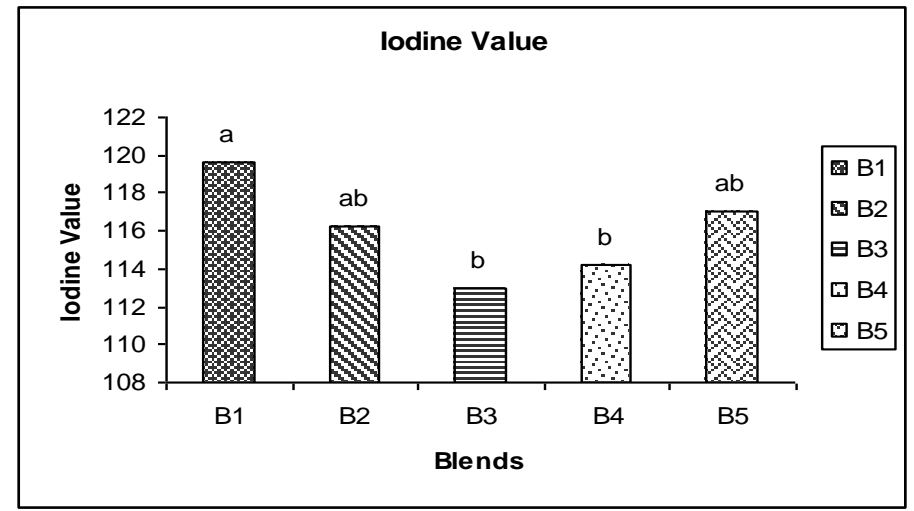

Figure 13 Iodine value of different blends

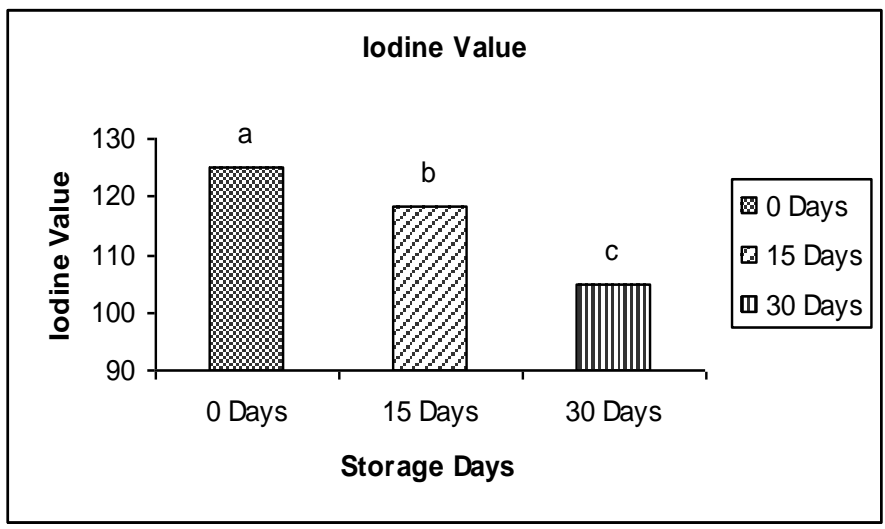

Figure 14 Effect of storage on iodine value

\section{Peroxide value}

The results revealed to the peroxide value of different chemically interesterified vegetable oil blends B1, B2, B3, B4, and B5 were found and is presented in (figure 15 and 16). The statistical analysis shows that peroxide value increased as the storage period increased which is in correlation with the results as observed by (Pfeuffer $\boldsymbol{e t}$ al., 1995; Basturk et al., 2007). Maximum value was observed after 30 days. The result shows that the peroxide value difference between different blends of interesterified oils is less significant as compared to peroxide value during storage. Similar types of results were observed by (Young, 1983) As the storage period increased the peroxide value of different chemically interesterified blended vegetable oils (soybean and cottonseed oils) was also increased. 


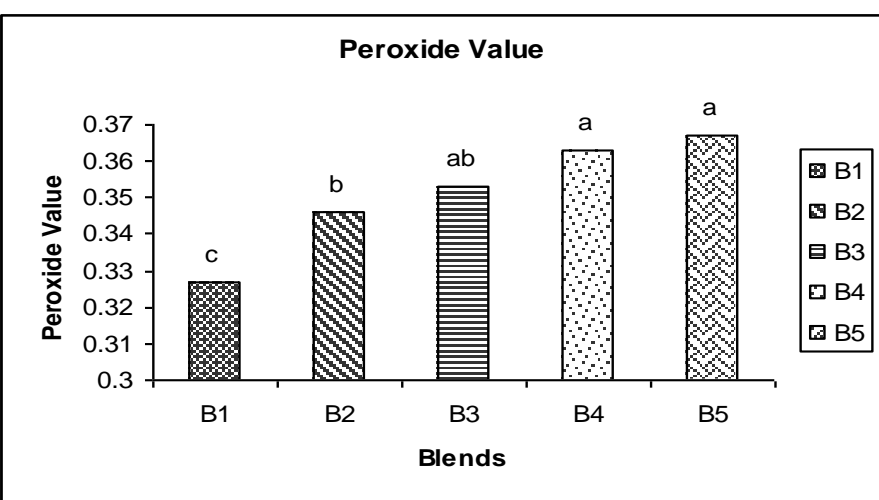

Figure 15 Peroxide value of different blends

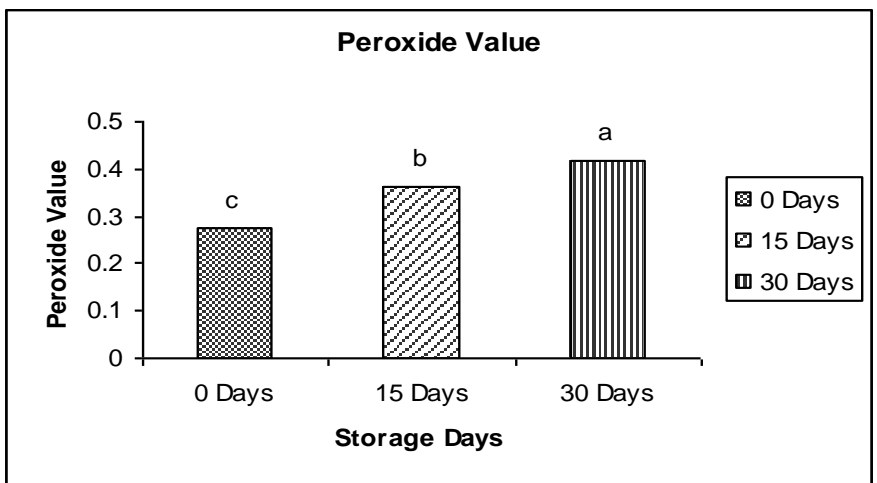

Figure 16 Effect of storage on Peroxide value

\section{Saponification value}

The results revealed to the saponification value of different chemically interesterified vegetable oil blends B1, B2, B3, B4, and B5 were found and is presented in (figure 17 and 18). The statistical analysis shows that saponification value increased as the storage period increased which is in correlation with the results as observed by (Rodriguez et al., 2001; Hosseinian et al., 2004) Maximum saponification value was observed after 30 days of storage interval. Similar types of results were observed by (Boran et al. 2006). This is due to increase in free fatty acid contents and decrease in long chain fatty acids. Saponification value difference between different blends of interesterified oils is less significant as compared to saponification value during storage.

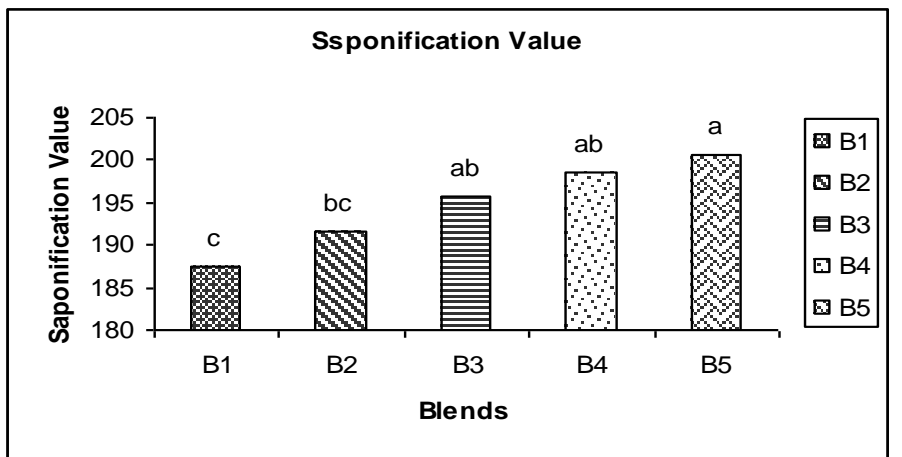

Figure 17 Saponification value of different blends

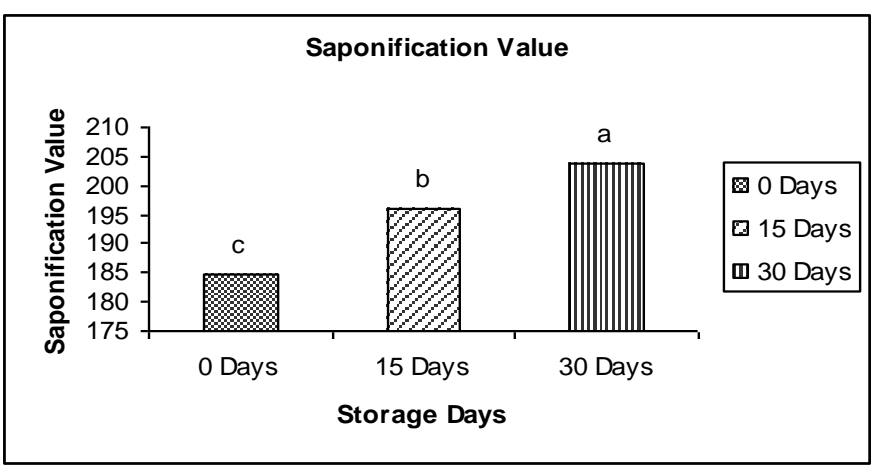

Figure 18 Effect of storage on saponification value

\section{Rancidity test}

The rancidity result was slightly pink for B1, B2, B3, B4, and B5 found initially but later shown more rancidity during storage. Rancidification is the decomposition of fats, oils and other lipids by hydrolysis or oxidation, or both Hydrolysis will split fatty acid chains away from the glycerol backbone in glycerides. These free fatty acids can then undergo further auto-oxidation. Oxidation primarily occurs with unsaturated fats by a free radical-mediated process.

\section{Sensory evaluation}

The sensory evaluation is a very important criterion in food industry. A panel of five judges from the postgraduate students of National Institute of Food Science \& Technology evaluated the samples for appearance, odor and overall acceptability. Sensory evaluation is a scientific technique that uses human senses to judge and evaluate the quality of foods and materials. Panel evaluations are used to detect and describe the organoleptic characteristics of food and non-food products. These tests provide an indicator of the acceptability of a product. Sensory evaluation can be used for ingredient/processing/packaging evaluations, shelf life testing, competitive comparisons, research applications. Sensory evaluation relies on precise and formal tests including difference, descriptive and affective tests that are continually being updated The results in (Figure 19) showed that maximum mean score was obtained by blend B3. While minimum mean score given by judges to blend B5 during the appearance evaluation of interesterifed oils. Effect of storage on the appearance of interesterified oils (Figure 20) showed that 0 day or $1^{\text {st }}$ day evaluation gives good results but with the passage of time results are not good and there is a decrease in sutibility with the passage of time. The results in (Figure 21) showed that maximum mean score was obtained by blend B3. While minimum mean score given by judges to blend B5 during the odor evaluation of sample oils. Effect of storage on the odor of interesterified oils (Figure 22) showed that 0 day or $1^{\text {st }}$ day evaluation gives good results but with the passage of time results are not good and there is a decrease in sutibility with the passage of time The results in (Figure 23) showed that maximum mean score was obtained by blend B3. While minimum mean score given by judges to blend B5 during the overall acceptability evaluation of sample oils. Effect of storage on the overall acceptability of interesterified oils (Figure 24) showed that 0 day or $1^{\text {st }}$ day evaluation gives good results but with the passage of time results are not good and there is a decrease in suitability with the passage of time.

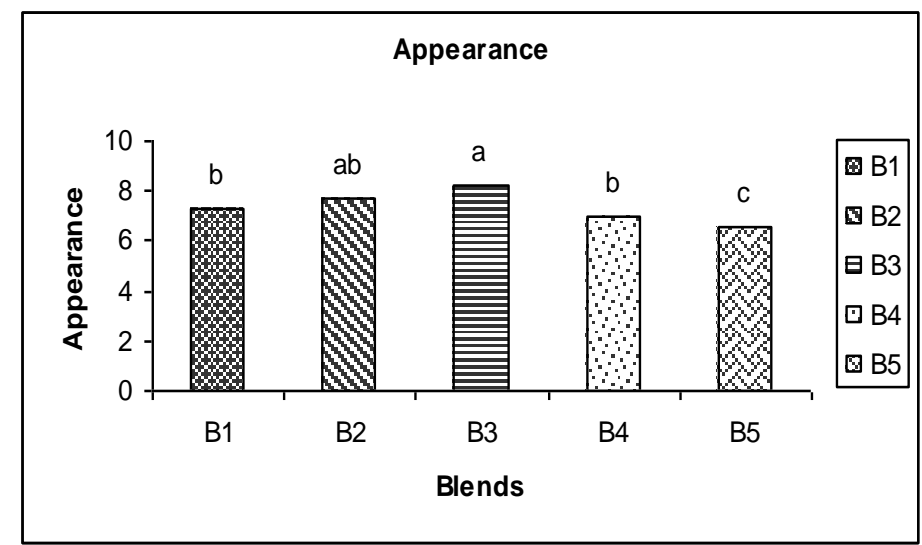

Figure 19 Appearance evaluation of different blends

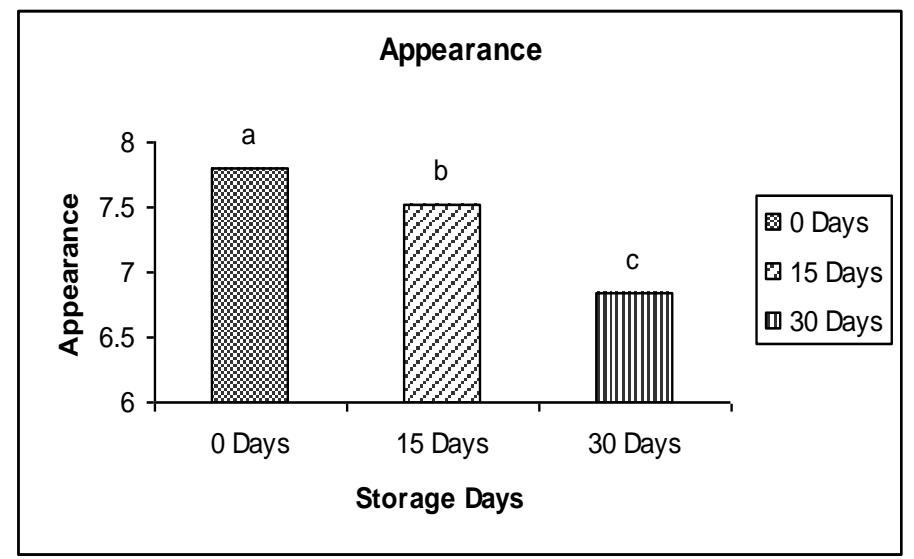

Figure 20 Effect of storage on appearance 


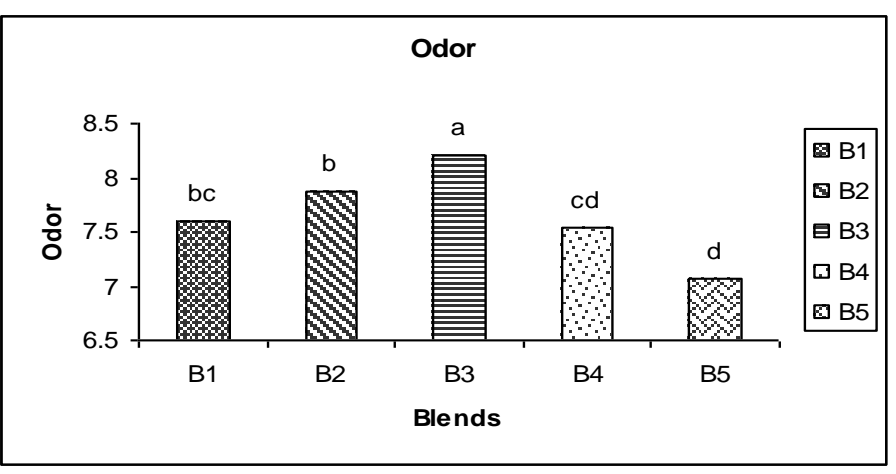

Figure 21 Odor evaluation of different blends

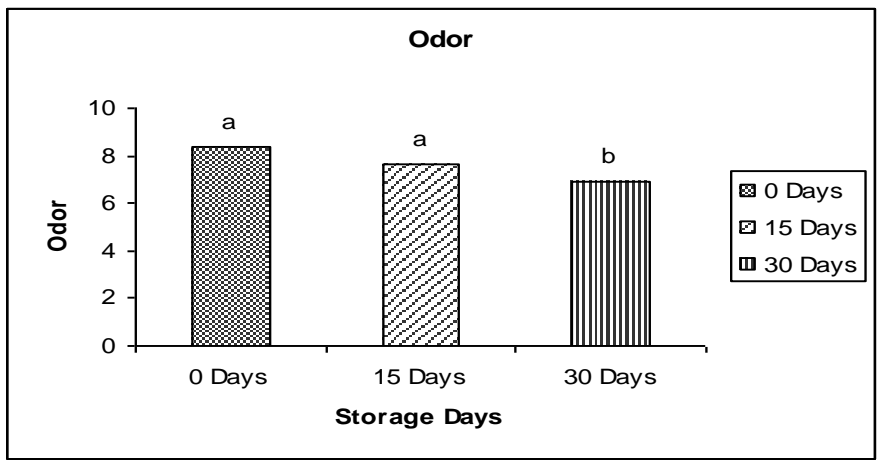

Figure 22 Effect of storage on odor

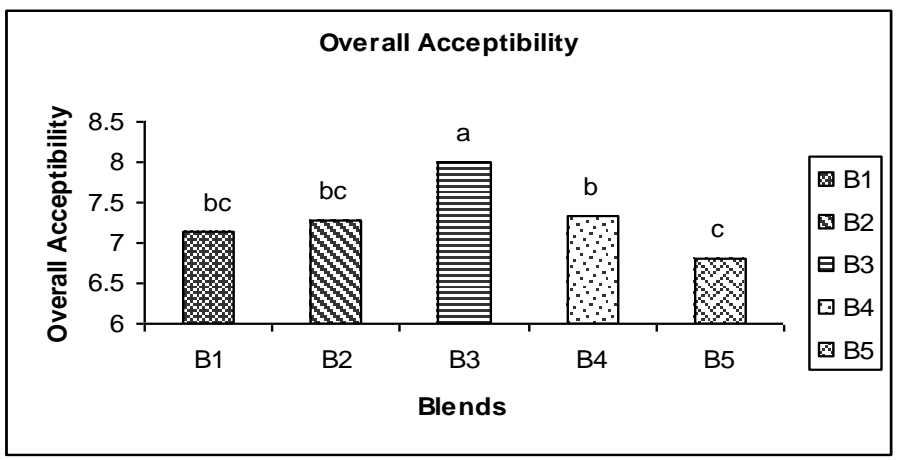

Figure 23 Overall acceptability of different blends

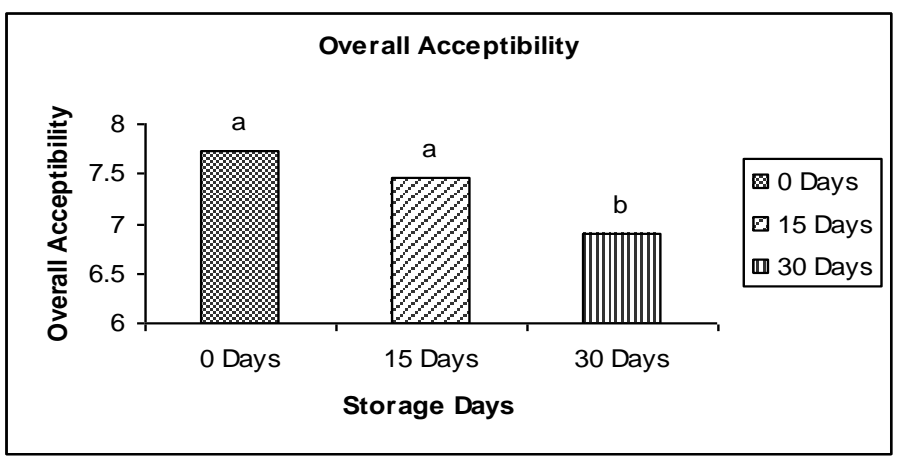

Figure 24 Effect of storage on overall acceptability

\section{CONCLUSION}

Chemically interesterified blended oils were analyzed after 0, 15 and 30 days of interval for different physical and chemical properties like refractive index, specific gravity, color, melting point, free fatty acids, iodine value, peroxide value, saponification value and rancidity. The results revealed that refractive index, specific gravity, color, melting point, free fatty acids value, peroxide value and saponification value increased while iodine value decreased with the passage of time. Further studies showed that storage had a highly significant effect on color, melting point, free fatty acids value, iodine value, peroxide value and saponification value. The effect of storage was non-significant for parameters like specific gravity and refractive index.

\section{REFERENCES}

Al-Zamily, R., \& S. Al-Hakim. (1987). Research on deep frying of foods 1. Evaluation of local commercial fats and oils in deep frying of potato chips. Iraqi Journal of Agriculture Science Zanco, 5(1), 113-124.

AOAC. (1990). Official methods of analysis. $15^{\text {th }}$ ed., Association of Official Analytical Chemists, Washington, DC, USA.

AOCS. (1989). Official methods and recommended practices of analysis. $4^{\text {th }}$ ed. American Oil Chemist's Society, Champaign, IL, USA.

Basturk, A., Javidipou, I., \& Boyaci. I.H. (2007). Oxidative stability of natural and chemically interesterified cottonseed, palm and soybean oils. Journal of Food Lipids, 14, 170-188. https://doi.org/10.1111/j.1745-4522.2007.00078.x .

Boran, G., Karacam, H., \& Boran, M. (2006). Changes in the quality of fish oils due to storage temperature and time. Food Chemistry, 98, 693-698. https://doi.org/10.1016/j.foodchem.2005.06.041.

Boyaci, I.H., Karabulut, I., \& Turan, S. (2003). Slip melting point estimation of fat blends before and after interesterification on their fatty acid composition. Journal of Food Lipids, 10, 193-202. https://doi.org/10.1111/j.17454522.2003.tb00015.x.

Cho, F., \& Deman, J.M. (1993). Physical properties and composition of low trans canola/palm oil blends partially modified by chemical interesterification. Journal of Food Lipids, 1(1), 53-68. $\quad$ https://doi.org/10.1111/j.17454522.1993.tb00233.x

Daniels, R.L., Kim, H.J., Min, D.B. (2006). Hydrogenation and interesterification effects on the oxidative stability and melting point of soybean oil. Journal of Agriculture and Food Chemistry, 54(16), 60116015. https://doi.org/10.1021/jf053263r.

Dimick, P.S. (1991). Principles of cocoa butter crystallization. Manufacture of Confectionary, 71(5), 109-114.

Dogan, S.I., I. Javidipour and T. Akan. 2007. Effects of interesterified palm and cotton seed oil blends on cake quality. International Journal of Food Science \& Technology, 42, 157-164. https://doi.org/10.1111/j.1365-2621.2006.01178.x

Fattahi-far, E., Sahari M.A., \& Barzegar,V. (2006). Interesterification of tea seed oil and its application in margarine production. Journal of American Chemical Oil Society, 83(10), 841-845. https://doi.org/10.1007/s11746-006-5035-9.

Hosseinian, F.S., Rowland, G.G., Bhirud, P.R., Dyck, J.H., \& Tyler, R.R. (2004) Chemical composition and physico-chemical and hydrogenation characteristics of high-palmitic acid solin (low-linolenic acid flaxseed) oil. Journal of American Chemical Oil Society, 81(2), 185-188. https://doi.org/10.1007/s11746-004-0879$\underline{6}$.

Hui, Y.H. (1996). Bailey's industrial oil and fat products. $5^{\text {th }}$ ed., Wiley Interscience Publications, New York, NY, USA. 125-58 p.

Hurtova, S., Schmidt, S., Zemanovic, J., Simon, P., \& Sekretar, S. (1996). Random interesterification of fat blends with alkali catalysts. Fett-Lipid, 98(2), 60-65. https://doi.org/10.1002/lipi.19960980205.

Idris, A.N., \& Dian, N.L.H.M. (2005). Interesterified palm products as alternatives to hydrogenation. Asian Pacific Journal of Clinical Nutrition, 14(4), 396-401.

Karabulut, I., Turan, S., \& Ergin, G. (2004). Effects of chemical interesterification on solid fat content and slip melting point of fat/oil blends. European Food Research Technology, 218, 224-229. https://doi.org/10.1007/s00217-003-0847-4

Konishi, H., Neff, W.E., \& Mounts, T.L. (1993). Chemical interesterification with regioselectivity for edible oils. Journal of the American Oil Chemists Society, 70(4), 411-415. https://doi.org/10.1007/bf02552716

Kowalski, B., Tarnowska, K., Gruczynska, E., Bekas, W. (2004). Chemical and enzymatic interesterification of beef tallow and rapeseed oil blend with low content of tallow. Journal of Oleo Science, 53(10), 479488. https://doi.org/10.5650/jos.53.479.

Larmond, E. (1987). Laboratory methods for sensory evaluation of foods. Deptt. Agric. Canada. Publ. No.1637/E.

Liu, L. (2004). How is chemical interesterification initiated: Nucleophilic substitution or $\alpha$-proton abstraction?. Journal of the American Oil Chemists Society, 81(4), 331-337. https://doi.org/10.1007/s11746-004-0903-x.

Mascioli, E.A., Mclennan, C.E., Schaefer, E.J., Lichtenstein, A.H., Hoy, C.E., Christensen, M.S., Bistrian, B.R. (1999). Lipidemic effects of an interesterified mixture of butter, medium-chain triacylglycerol and safflower oils. Lipids, 34(9), 889-894. https://doi.org/10.1007/s11745-999-0437-x .

Nawar, W.W. (1996). Lipids, in food chemistry, $3^{\text {rd }}$ ed., Marcel Dekkar, Inc., New York, NY, USA. 225-319.

Norizzah, A.R., Chong, C.L., Cheow, C.S., Zaliha, O. (2004). Effects of chemical interesterificarion on physicochemical properties of palm strein and palm kernel $\begin{array}{llll}\text { olein blends. Food Chemistry, } & \text { 229-235. }\end{array}$ https://doi.org/10.1016/j.foodchem.2003.09.030

O’Brien, R.D. (2004). Fats and oils processing. In: Fats and oils: Formulating and processing for applications. CRC Press, Florida. 57-174.

Petrauskaite, V., Greyt, W.D., Kellens, M., Huyghebaert, A. (1998). Physical and chemical properties of trans-free fats produced by chemical interesterification of vegetable oil blends. Journal of the American Oil Chemists' Society, 75(4), 489493 https://doi.org/10.1007/s11746-998-0252-z 
Pfeuffer, M., Greyt, W.D., Schoppe, I., Barth, C.A., Huyghebaert, A. (1995). Effects of interesterification of milk fat on plasma lipids of miniature pigs. International Dairy Journal, 5, 265-273. https://doi.org/10.1016/09586946(94)00003-8.

Ramli, N., Said, M., Loon, N.T. (2005). Physicochemical characteristics of binary mixtures of hydrogenated palm kernel oil and goat milk fat. Journal of Food Lipid, 12, 243-260. https://doi.org/10.1111/j.1745-4522.2005.00021.x

Rodriguez, A., Castro, E., Salinas, C.M., Lopez, R., Miranda, M. (2001) Interesterification of tallow and sunflower oil. Journal of the American Oil Chemists' Society, 78(4), 431-436. https://doi.org/10.1007/s11746-001-0280-5.

Rodrigues, J.N., \& Gioielli, L.A. (2003). Chemical interesterification of milk fat and milkfat-corn oil blends. Food Research International, 36, 149159. https://doi.org/10.1016/s0963-9969(02)00130-8 .

Rousseau, D., Hill, A.R., \& Marangoni, A.G. (1996). Restructing butter fat through blending and chemical interesterification. 3. Rheology. Journal of the American Oil Chemists' Society, 73(8), 983989. https://doi.org/10.1007/bf02523405.

Schmidt, S., Silvia, H., Jaroslav, Z., Stanislav, S., Peter, S., \& Paul, A. (1996). Preparation of modified fats from vegetable oil and fully hydrogenated vegetable oil by randomization with alkali catalysts. Food Chemistry, 55(4), $343-$ 348. https://doi.org/10.1016/0308-8146(95)00113-1.

Shiela, P.M., Sreerama, Y.N., \& Krishna, A.G.G. (2004). Storage stability evaluation of some packed vegetable oil blends. Journal of the American Oil Chemists' Society, 81(12), 1125-1129. https://doi.org/10.1007/s11746-004-1029$\mathrm{x}$.

Smith, L.L.W., \& Minor, L.J. (1974). Food Service Science. AVI Pub. Co. Inc., Westport, Connecticut, 481-484.

Sreenivasan, B. (1978). Interesterification of fats. Journal of the American Oil Chemists' Society, 55(6), 796-805 6 citations from patents https://doi.org/10.1007/bf02682651.

Steel, R.G.D., Torrie, J.H., Dickey, D. (1997). Principles and procedures of statistics. A biometrical approach. $3^{\text {rd }}$ ed., McGraw Hill Book Co, New York, NY, USA.

Timms, R.E. (1985). Physical properties of oils and mixtures of oils. Journal of the American Oil Chemists' Society, 62(2), 241-249. https://doi.org/10.1007/bf02541385.

Tyagi, V.K., \& Vasishtha, A.K. (1996). Changes in the characteristics and composition of oils during deep-fat frying. . Journal of the American Oil Chemists' Society, 73(4), 499-506. https://doi.org/10.1007/bf02523926

Yoon, S.H., Kim, S.K., Kim, K.H., Kwon,T.W., Teah, Y.K. (1987). Evaluation of physico-chemical changes in cooking oil during heating. Journal of the American Oil Chemists' Society, 64(6), 870873. https://doi.org/10.1007/bf02641496

Young, F.V.K. (1983). Palm Kernel and coconut oils: Analytical characteristics, process technology and uses. Journal of the American Oil Chemists' Society, 60(2), 374-379. https://doi.org/10.1007/bf02543521.

Zeitoun, M.A.M., Neff, W.E., List, G.R., \& Mount, T.R. (1993). Physical properties of interesterified fat blends. Journal of the American Oil Chemists' Society, 70(5), 467-471. https://doi.org/10.1007/bf02542577.

Zhang, H., Xu, X., Mu, H., Nilsson, J., Adler-Nissen, J., \& Hoy, C. (2000). Lipozyme IM-catalyzed interesterification for the production of margarine fats in a $1 \mathrm{~kg}$ scale stirred tank reactor. European Journal of Lipid Science Technology, 102(6), 411-418. https://doi.org/10.1002/1438-9312(200006)102:6<411::aidejlt411>3.0.co;2-t . 